\title{
Compliance of High-rise Buildings Vertical Accessibility Components with Universal Design Strategies: A Case Study of Covenant University, Ota, Nigeria
}

\author{
Sholanke A. B., Adelowo I. E. , Gbotosho J. O. \\ Department of Architecture, College of Science and Technology, Covenant University, Ota, Nigeria
}

Received May 16, 2020; Revised July 2, 2020; Accepted July 20, 2020

\section{Cite This Paper in the following Citation Styles}

(a): [1] Sholanke A. B., Adelowo I. E., Gbotosho J. O. , "Compliance of High-rise Buildings Vertical Accessibility Components with Universal Design Strategies: A Case Study of Covenant University, Ota, Nigeria," Civil Engineering and Architecture, Vol. 8, No. 5, pp. 735 - 749, 2020. DOI: 10.13189/cea.2020.080501.

(b): Sholanke A. B., Adelowo I. E., Gbotosho J. O. (2020). Compliance of High-rise Buildings Vertical Accessibility Components with Universal Design Strategies: A Case Study of Covenant University, Ota, Nigeria. Civil Engineering and Architecture, 8(5), 735 - 749. DOI: 10.13189/cea.2020.080501.

Copyright $\odot 2020$ by authors, all rights reserved. Authors agree that this article remains permanently open access under the terms of the Creative Commons Attribution License 4.0 International License

\begin{abstract}
In recent times, with the increase in population, land areas that can accommodate the traditional school design model are becoming difficult to come by in urban areas or expensive. Therefore, for urban schools to accommodate the increasing population, school designs have shifted from outward horizontal arrangements to upward vertical designs. Consequently, this study examined the compliance of vertical accessibility components in high-rise buildings in Covenant University, Ota in Nigeria, with universal design strategies, with a view to identifying areas for further improvements, towards contributing to ways of promoting social inclusion in educational environments. The research is a qualitative case study of a tertiary institution that investigated two high-rise buildings on the university campus. An observation guide developed for the study and a digital camera were used to collect primary field data. The data were content analysed and presented using descriptive approach with the aid of texts and pictures. The findings revealed that ramps, steps/staircases and lifts are the vertical accessibility components provided in the high-rise buildings, all of which were found to exhibit various levels of inconsistencies with universal design strategies. One of the key recommendations of the study is to retrofit the buildings with necessary accessible features where they are lacking or inappropriately provided, where possible. The study will be useful to researchers, students, educators, policy makers and building design professionals in
\end{abstract}

addressing issues relating to universal design of the built environment, particularly as it relates to the provision of equitable vertical movement features in high-rise public buildings.

Keywords Universal Design, High-rise Buildings, Accessibility, Usability, Vertical Movement Components, Covenant University

\section{Introduction}

In recent times, many families have migrated to urban centres, as it is becoming more desirable to live in urban areas that provide people with varieties of amenities, facilities and services for improving quality of living. One of such conveniences is the availability of good schools. It is however observed that not every pupil that leaves secondary school in urban areas move on to a tertiary institution. A sizeable number of students in this category are those with disabilities, as a sizable population of people in Nigeria are living with a form of disability. Though it can be argued that there are established special schools that can cater for the peculiar needs of the physically challenged, this does not imply that regular schools should not be readily available and accessible to this user group. A school ought to be a citadel of learning where people of 
diverse background can come together to learn and acquire formal education, regardless of their gender, race, color, ability or disability.

With the emergence of globalisation that comes with population explosion in urban areas, land areas that can support and accommodate the traditional horizontal school design model are no longer readily affordable and financially viable. Therefore, for urban schools to accommodate the increasing population, Hadley [1] advanced that school designs must move from designing outward to designing upward. Consequently, many school buildings are now being designed vertically (upwards) as high-rise buildings, rather than spreading horizontally (outwards). With the emergence of this new model of school buildings, the demand for vertical movement provisions that can cater for the accessibility and usability needs of everyone, is considered fundamental to making university education equitable and inclusively available, accessible and usable to anyone that can afford it.

In an academic environment, it is imperative to provide a barrier free setting for all students to enable them experience and benefit from all aspects of education within the learning environment. Universal Design (UD) has the capacity to change the status quo of universities into institutions that provide users with equal opportunities to learn, excel and attain their true prospects, despite prevailing circumstances of age, size or physical capability [2]. The UD ideology advocates the design of products and the built environment to be accessible and usable by all category of users without any need for adaptation or a special kind of design solution [3]. In an academic environment, a key factor that contributes to a barrier free setting is the provision of appropriate accessibility and usability features. With the emergence of vertical school buildings, it is important that all necessary features that can make school buildings universally accessible to all are in place. The facilities, including vertical movement components, should meet the needs of all user categories, regardless of their ability or inability. To ascertain that academic settings are inclusive in nature with regards to the provision of accessibility components, there is a need to investigate existing schools to establish the conformity of their accessibility features with UD strategies, towards pinpointing areas for enhancements.

Covenant University has attained the status of a highly regarded university in Nigeria and Africa. The institution is working towards becoming one of the top ten high-level universities in the world [3], in accordance with vision 102022 proclaimed by the Chancellor of the university, Bishop (Dr.) David Oyedepo in 2012. To be one of the best universities in the world will require that the institution's buildings and environment are accessible and usable for everyone in line with the UD ideology. It is on this note, that this study investigated the compliance of vertical accessibility components of high-rise buildings with UD strategies in the university, with a view to identifying areas for further improvements, towards contributing to ways of promoting social inclusion in educational environments. Covenant University was selected as the study location, due to its rating as the best ranked university in Nigeria in the 2020 Times Higher Education World Rankings of Universities [4].

The scope of the study is limited to investigating only the general vertical movement components provided for users of high-rise buildings in the university. The vertical movement features were specifically targeted as the focus of the investigation, because they require more special considerations to make them usable for everyone, compared to horizontal movement features, whose principal requirement is the provision of adequate space that can allow for mass movement or at least allow two wheelchair users pass side by side.

Some of those who will find the study a useful reference document, are: researchers, students, educators, policy makers and building design professionals. The findings of the study will also be useful for benchmarking Covenant University's high-rise buildings compliance level with UD strategies, against those of other institutions in Nigeria and around the globe. The structure of the paper comprises of an abstract, an introduction, a literature review, a methodology, a presentation of the analysed field data with a discussion of findings, as well as a conclusion, acknowledgements and references sections. Field data for the study was gathered between December 2019 and February 2020.

\section{Literature Review}

\subsection{Universal Design Paradigm}

In the past, design professionals did not realise that when physically challenged persons encounter an obstacle, it makes them handicapped [5]. Diversity in humans is not a new knowledge as each person is uniquely different from the other and as time goes on, we are subject to more changes that lead to more diversity. There are a lot of things that separate us from one another. Some of these things include: gender, race, background, color, abilities or disabilities. Therefore, it is very important to create a world where every person can feel accepted and everyone has equal rights to all facilities and opportunities [6].

UD is a design concept that aims to cater for the needs of every person regardless of their abilities at little or no extra cost. It is defined as the design of environments, buildings and products to be utilised by everyone without requiring any modification or specialised design. UD is both sustainable and cost effective, as it is targeted at designing for every individual. It also helps to reduce cost when considered at the beginning of the design process, rather than when the need arises after a building has been built [7]. UD is a useful concept for enhancing learning for students with disabilities. The promotion of UD in the education sector has led to the development of specially 
designed hardware and software applications for enhancing learning for the physically challenged [8].

According to a global assessment on topics pertaining to disability issued in 2011, over 25 million Nigerians have at least a disability, with about 3.6 million of them having difficulties functioning normally. This means that a large population of the society is living with disabilities in the country. This makes it important for buildings to be designed to accommodate the special needs of this user group in line with the UD ideology. UD is similar to accessible design, but in actual sense, it is a better alternative to it. While accessible design seeks to promote accessibility for people with disabilities (PWDs), UD seeks to promote and cater for the needs of everyone regardless of their abilities or inabilities $[9,10]$.

According to Sholanke, Adeboye, Alagbe, Fadipe \& Iyoha [11] and Copeland [12], UD is generally guided by seven principles proposed by the Centre for UD in North Carolina State University in America. The principles are: 1) Equitable Use: The design strategy should be of value and sought-after by any user group. 2) Flexibility in Use: Diversity of individual preference and skill should be reminiscent of the design. 3) Simple and Intuitive Use: The design should be easily understood without the need for conscious reasoning by the user. 4) Perceptible Information: The sensory input of the user should not hinder the ability of the design to transmit or pass information effectively to the user. 5) Tolerance for Error: The design should limit the possibility of occurring unintentional or unwanted acts. 6) Low Physical Effort: The design should require minimal physical effort to use and promote user comfort. 7) Size and Space for Approach and Use: The size and space allocated for approach, manipulation, reach and use of the design should be reasonable to allow for easy access regardless of the size, posture or mobility of the user.

The UD principles can be used for guiding and influencing a design procedure and concede the indication of disposable products and environments, as well as to evaluate existing architectural designs $[9,3]$. Where UD is applied at the design stage, its outcome benefits everyone as it accommodates user's diversity. For instance, it helps to create an environment that allows people to age, yet retain their independence. It also helps businesses have an edge over their counterparts. Nevertheless, some people still fail to fully implement UD criteria into designs because of some misconceptions about the idea. Two of these misconceptions identified by Rossetti [13] are that buildings that are universally designed appear unpleasant and conventional, as well as people getting the wrong impression that such buildings are planned solely for the handicapped. The author argued that these are false impressions, as UD features enhance the beauty of a building while making it functional and convenient for every user, rather than the physically challenged alone. What is convenient for a physically challenged person to access and use will most certainly be easily accessible and usable for able-bodied persons.

Rossetti [13] also corrected another delusion that a building that conforms with UD principles costs more, because of the distinctive features of UD present in the building. The author debunked this notion by arguing that a building that complies with UD concept stands to be valuable for a lifetime, thereby increasing the value of the building which makes it useful for as long as the building is in use. Also, people often think that a building designed with UD parameters requires more square footage. This the author also debunked by explaining that space planning is important in design, therefore, a universally designed building does not require more square footage outside just adequate room for navigation. The last mistaken belief identified by Rossetti [13] is that the adoption of UD strategies in a building makes it less likely to scale a building code scrutiny. The author clarified that based on the definition and nature of UD, its principles always adhere to established state and federal building codes. In cases of inquiry that may arise from the evaluation of the design, provision for local variation is usually made available.

Notwithstanding the various misconceptions surrounding UD ideology, the concept is considered significant to humans and has therefore gained global recognition and caught many researchers' interests lately. For instance, Sholanke, Adeboye \& Alagbe [9] investigated designs that constituted barriers to achieving UD in selected academic buildings in selected universities in Ogun State, Nigeria. The study is a qualitative survey that used observation guide and pictures to collect field data from nine academic buildings across three universities in the study area. The designed features found to constitute barriers to achieving UD in the various academic buildings in the selected universities were mainly accessibility features that are not suitable for the use of the physically challenged. Some of such features include: lack of dropped kerbs to external walkways and open drainage beside walkways, lack of accessible parking spaces, inadequate doors, steps, ramps, handrails and access routes dimensions, and provision of steps without ramps where there are changes in levels.

Likewise, Hibatullah [14] evaluated the accessibility components of the School of Engineering buildings at the University of Jordan. The researcher carried out the study in order to examine the level of accessibility in existing higher learning institutions that are in accordance with Jordanian Nation Building Codes - Building Requirement Code for the Disabled (BRCD), towards the promotion of the "right to work" and the "right to get higher education" for PWDs in line with the UD ideology. The study is a qualitative research that utilised interviews with students and staff members with disabilities to gather data. To investigate if the requirements for renovation in public buildings and education buildings implement the BRCD, 
an observation guide was used to collect data. The result of the study revealed that the BRCD requirements did not cater for the minimum requests of PWDs, because the BRCD was mainly concerned with people with physical disabilities, with less consideration made for people living with hearing or visual impairment.

In addition, Ibem, Oni, Umoren \& Ejiga [15] appraised the UD compliance of museum buildings in Southwest Nigeria. The authors conducted their research to determine how the design, planning and construction of selected museum buildings and facilities complied with the principles of UD and how they promoted the satisfaction of users in the study area. The study is a multiple case study research that used observation guide to gather field data from three museums in Southwest Nigeria. The museums were appraised based on three principles of UD which are: accessibility, approachability and usability. The result showed that all the museums complied with the approachability principle, but fell short in accessibility and usability requirements.

Similarly, in a study by Sholanke, Adeboye, Oluwatayo $\&$ Alagbe [3], the researchers used the seven principles of UD developed by The Center for Universal Design in North Carolina State University to assess the features of the main entrances of five selected public buildings in Covenant University, Ota in Nigeria. The features assessed include: carparks, pedestrian walkways, entrance porches, entrance steps, entrance ramps, floor finishes and entrance doors. The result indicated that all the buildings fell short of meeting UD accessibility requirements. For instance, ramps were not provided alongside steps at the main entrances of majority of the buildings in line with the demand of UD. Where a ramp was found, such ramp did not conform with UD standard. Also, several steps situated at the main entrances of the buildings were found to be inconsistent with UD requirements.

Furthermore, a UD study that centred around the everyday life of elderly adults in an adult home was conducted by Mustaquim [16]. The research was carried out to gain insight into the performance of the different variables associated with the UD concept and how the elderly adults identified with them in their day to day activities in the home. The study employed quantitative means to gather data in Montgomery County's Arcola Health and Rehab Centre, Maryland, USA, over a period of four weeks. A total of thirty-one patients, purposively selected based on their cognitive abilities, took part in the survey. The result showed that UD variables that defined knowledge acquisition present a substantial modification in its description, through the parameters that describe perception. The result also underscored the significance of understanding the UD principles, which was discovered not to be adequate for the design of suitable homes that are inclusive and accessible for elderly adults. Though the study met its target, being a case study of a single adult home means that the result cannot be generalised.
Also, a UD interior design application study was conducted in shopping malls in Surabaya by Yusita, Yong $\&$ Thamrin [17]. The study was carried out to identify challenges associated with entrance and circulation facilities, with a view to address the design challenges that may arise in shopping centres around Surabaya. The study employed qualitative research methodology. Data was collected from fifteen malls in the study area. The malls were selected based on the following criteria: mall diversity, location distribution, popularity and the establishment distribution. Observation and documentation were used to gather field data. A significant problem discovered in most of the malls was lack of ramped access at their entrances. And where ramps were found, such ramps lacked handrails in line with a key UD requirement. The research findings indicated that the accessibility needs of the physically challenged was not given enough attention in the development of the shopping malls.

In addition, Kadir \& Jamaludin [18] investigated the level of implementation of Malaysian standards and UD in structures accessible by the public in Putrajaya. The evaluation was based on ability of the facilities provided to attain the standard of existing requirements and guidelines applicable to Malaysia. The research is a case study that employed qualitative research approaches. The five buildings that were assessed for the purpose of the study were chosen based on how frequent they are visited. The buildings include: a government administrative office, an educational foundation, a health service centre, a conference/event centre and a worship centre. The study found that the only thing that was lacking in the buildings is the absence of appropriate accessibility features to the information counter.

Generally, previous UD studies found that center around the physical environment, established that little or no consideration were made for accessibility and usability features that meet the needs of PWDs in majority of the buildings investigated. It was also observed from most of the studies that the focus of the researchers, was mainly on low-rise public buildings. Hence, there is a dearth of detailed information on the UD compliance level of vertical accessibility components in high-rise buildings, particularly in academic environments in Nigeria. Due to the peculiar nature of high-rise buildings, it is imperative that their vertical movement provisions conform with UD requirements in academic settings, towards promoting inclusive education. Though Sholanke et al. [9] and Hibatullah [14] investigated accessibility in some academic buildings in university environments in Nigeria and Jordan respectively, the buildings the researchers examined are mainly low-rise buildings. This did not provide the necessary feedback on the UD compliance level of accessibility components such as lifts that are mainly a requirement in high-rise buildings in the study areas. Consequently, this study was conceived to fill this gap by investigating the UD compliance level of vertical 
accessibility components of high-rise buildings in Covenant University, Ota, Nigeria, with a view to identify areas for possible improvement, towards making contributions on ways of promoting social inclusion in educational environments in Nigeria.

\subsection{Accessibility in High-rise Buildings}

The criteria used to define a high-rise building vary across the globe. The Building Code of Hyderabad, India highlighted the requirements for a high-rise building as having at least four floors, or fifteen to eighteen meters or more in height [19]. Emporis Standards [20] defined a high rise as a multi-story structure between thirty-five to hundred meters high, or a building whose altitude is not determined, but is in the range of twelve to thirty-nine floors. In the United States, National Fire Protection Association (NFPA) [21] described a high-rise as a building higher than seventy-five feet (twenty-three meters), or about seven storeys. However, according to the National Building Code [22] used in Nigeria, any building that is more than four floors is classified as a high-rise building in the country. Such a building is expected to be provided with specialised feature for vertical movement that will accommodate the accessibility and usability needs of everyone, including the physically challenged.

Accessibility, basically covers the extent to which a building's point of entry provides ease of movement to the users, with the inclusion of people with physical disabilities into the spaces and facilities within the building, in order to enable them perform obligatory activities and functions. Generally, vertical movement components used in public buildings include: stairs, ramps, lifts, escalators and travellators. The most common of these lots are stairs, ramps and lifts. The three accessibility components are generally used in most high-rise buildings for easy vertical movement of users, especially in academic environments.

\subsection{Vertical Accessibility Components Universal Design Strategies in Academic Environments}

The usual vertical accessibility components that are generally provided in academic environments include: stairs, ramps and lifts. Each of these access features have specific standard requirements, in order to enable them cater for the accessibility needs of every user that intends to use any of them to access a building, irrespective of the user's age or disability. Vertical movements in a building can be classified into two categories. The first is where there is a change in level on a level plane on a floor, while the second is moving from one floor to another [23-25].

A Universal Design Handbook, Building for Everyone [26] provided useful guidelines for the design of stairs, ramps and lifts. The provisions of the guidelines are as follows:

\subsubsection{Staircases}

Staircases or stairs can be used as a means of vertical movement in buildings when there is a change in level on the level plane which is often the entrance to a building, or from one floor to another. There are various specifications that must be followed in order to design stairs that can be accessible and usable to most user groups. Key among these specifications include:

(1) The dimension of a stair must be consistent throughout its flight with tread and going dimensions ranging from $300 \mathrm{~mm}-450 \mathrm{~mm}$ and riser dimensions ranging from $150 \mathrm{~mm}-180 \mathrm{~mm}$.

(2) The face of the riser should not be less than $60^{\circ}$.

(3) Step risers should be rigid, since open risers can cause visual discomfort.

(4) The clear dimension of the inner stairs, which is measured between the handrails, should not be less than $1200 \mathrm{~mm}$.

(5) The total height of a step flight between landings should not surpass $1800 \mathrm{~mm}$.

(6) Stairs with two or more successive flights should ensure that the number of steps in each flight are as the same as possible.

(7) Stairs which are not enclosed should be put directly in line with a corridor or main circulation path.

(8) Stairs that are enclosed should continuously provide signs and directions that lead to the stairs.

(9) Railings attached to stairs should be placed $900 \mathrm{~mm}-$ $1100 \mathrm{~mm}$ above the landings and above the stairs.

(10) Stairs that are enclosed should continuously provide signs and directions that lead to the stairs.

(11) Railings attached to stairs should be placed $900 \mathrm{~mm}-$ $1100 \mathrm{~mm}$ above the landings and above the stairs.

The aforementioned requirements for the design of an accessible stairs are illustrated in Figures 1 and 2 with all dimensions in millimeters.

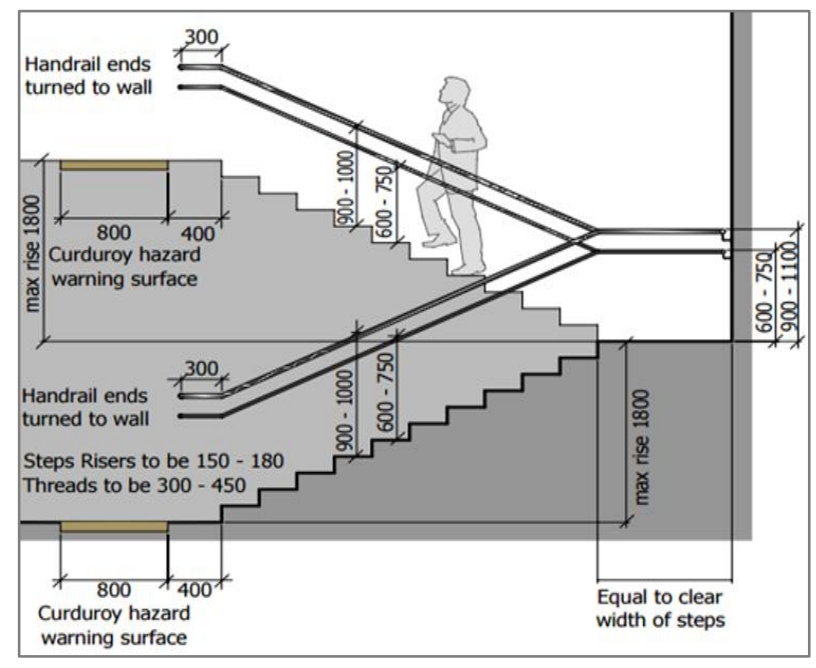

Source: Building for Everyone [26].

Figure 1. Stairs Details 


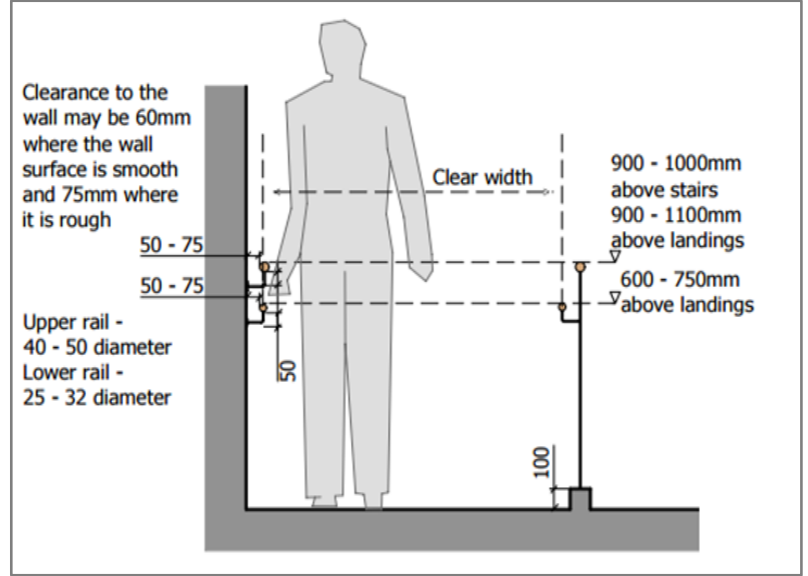

Source: Building for Everyone [26].

Figure 2. Handrails Details

\subsubsection{Ramps}

Ramps are mainly used as means of vertical movement when there is an alteration in level on the level plane. They can be used when there is a change in floor for very large buildings. In such a case, they require a large space to be very effective. However, ramps should be accompanied with stairs except in situations where the difference between the ground level and the level of the building is less than $300 \mathrm{~mm}$.

Ramps are more effective than stairs when entering into a building as they cater for the aged, the physically challenged and other categories of users. The following considerations should be put in place when designing an accessible ramp that can be usable for everyone:

i. Ramps should have a slope not greater than 1 to 20.

ii. The maximum rise between the landings should be $450 \mathrm{~mm}$.

iii. The maximum length of a ramp should be 9000 $\mathrm{mm}$ in accordance to the 1 to 20 gradient.

iv. When there are two consecutive ramps, they should be of the same slope and gradient.

v. It is important to avoid ramps with steeper gradients as they are dangerous to users.

vi. The distance between the low rail and the ramp is between $600 \mathrm{~mm}-750 \mathrm{~mm}$, whereas the distance between the top rail and the landing is between $900 \mathrm{~mm}-1000 \mathrm{~mm}$.
The stated requirements for the design of accessible ramps are illustrated in Figure 3 with all dimensions in millimeters.

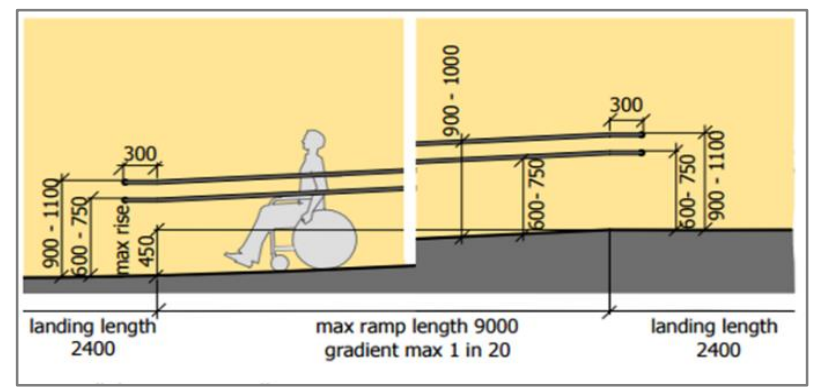

Source: Building for Everyone [26].

Figure 3. Ramp Details

\subsubsection{Lifts}

Lifts or Elevators are the most convenient means of passage from one floor to another for people that do not want to use staircases, especially in high-rise buildings. Lifts are mechanical devices that rely strictly on regular supply of electricity to function and be effective in a building. The following factors should be considered in the design of lifts:

- Lifts should permanently be positioned opposite stairways in a building to provide users an alternative means of passage. The location is important for users who are not fully comfortable using the lifts and want to access other floors easily.

- The location of lifts should be visibly indicated with signs from the entrance and other vital areas inside a building for easy direction.

- Lifts provided in public places should be able to accommodate people travelling with luggage.

- Lifts should have minimum internal dimensions of $1800 \mathrm{~mm}$ by $1800 \mathrm{~mm}$.

- Lift doors should be as wide as $950 \mathrm{~mm}$ to accommodate every category of user.

- Lift doors ought to open for at least 8 seconds to allow everyone exiting and entering the lift do so conveniently.

- There should be an obvious visual contrast between the lift door and the adjacent wall surfaces.

Figure 4 shows an illustration of the requirements of an accessible lift with all dimensions in millimeters. 

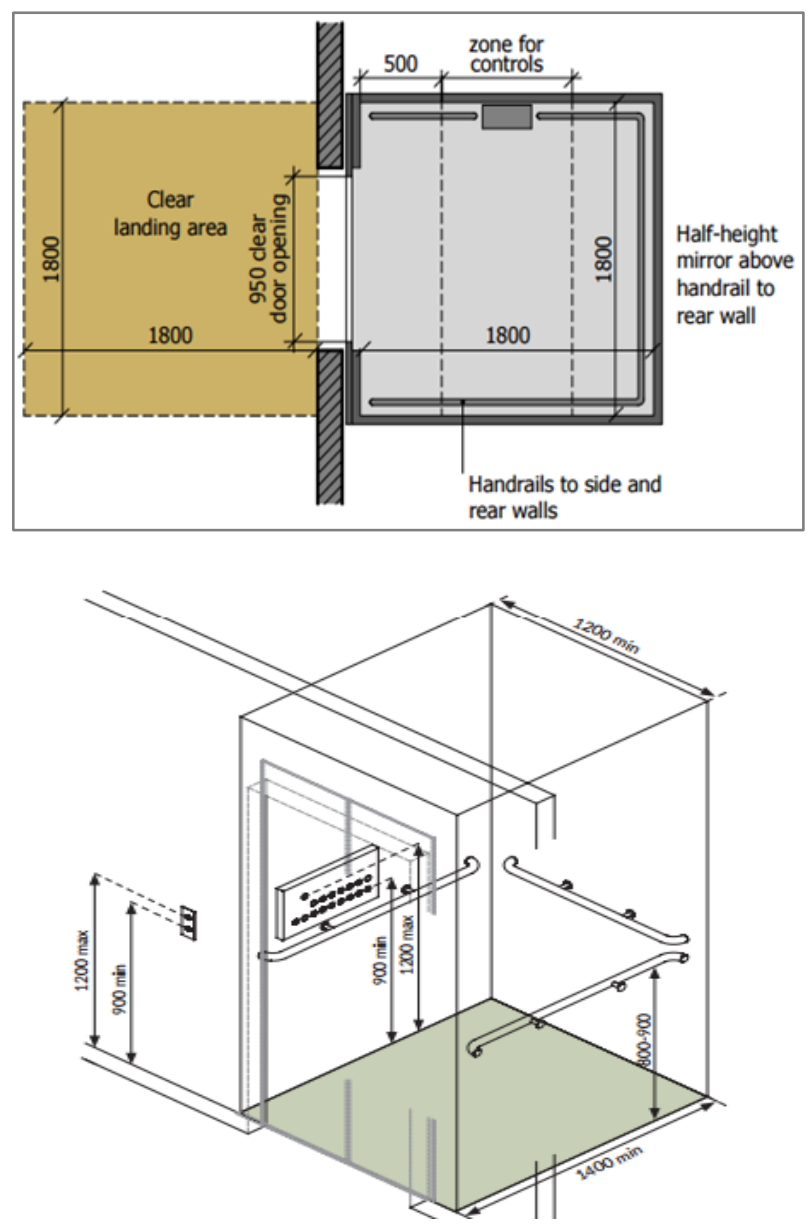

Source: Building for Everyone [26].

Figure 4. Lift Details

\section{Methodology}

The research is a case study of Covenant University, Ota in Nigeria, with a focus on high-rise buildings vertical movement components. The case study approach was considered suitable for carrying out the research, because the research was targeted at unfolding an existing situation. According to Yin [27], case study can be categorised into three: explanatory, exploratory and descriptive. All these approaches help to provide answers to research questions of how and why. Noor [28] explained that the purpose of a case study is not to examine the organisation as a whole, but direct the centre of interest to a specific area, feature or unit of analysis, in this case a university setting. As the study was out to compare what is existing to known standards, qualitative research methodology was considered the most appropriate method to execute the research and was employed. The study was targeted at evaluating the compliance level of vertical accessibility components in high-rise buildings with UD strategies. This necessitated the examination of what is existing in the selected buildings and the findings compared with UD strategies found in literature. According to Sholanke, Adeboye \& Alagbe [29], it is appropriate to use qualitative research methodology where the purpose of a research centres around examining, understanding and describing a phenomenon. Qualitative research approach is usually useful for investigating and unfolding the truth about the state of a situation, event or an item as is the case with this study.

To gather field data for the research, a thematic textual analysis of known UD strategies in literature was first conducted to collect secondary data that was used to develop an observation guide. The secondary data were collected from relevant published literature that were sourced for with the aid of Google search engine via the internet. Key among such literature are: the seven principles of UD developed by the Centre for UD in North Carolina State University in America, the Building for Everyone [26], as well as a PhD thesis by Sholanke [30] on UD compliance of academic buildings in Ogun State, Nigeria. The secondary data was analysed by textual analysis to sieve out relevant information that was useful for the development of the observation schedule. Based on the criteria used to judge high-rise buildings in Nigeria specified in the National Building code [22] mentioned earlier, only two buildings in the university campus fall under the category of high-rise buildings. The two buildings that constitute the study population of high-rise buildings are: The Senate Building with eight floors; and The Centre for Research, Innovation and Discovery Building, made up of seven floors. Because the study population is just two buildings, both buildings were adopted as the sample size and used for the research.

The study was designed as a qualitative research, hence all the data gathered, analysed and presented are qualitative in nature. Primary field data were gathered from the two buildings that constitute the sample size by the aid of the observation guide developed for the study, as well as pictures taken with a digital camera to document the findings and enrich data collected with the observation guide. The primary data obtained from the buildings were those pertaining to the vertical accessibility components. The data were content analysed and grouped in themes. The analysis involved comparing the data obtained with known UD standard strategies mentioned earlier to determine their compliance level with the standards. The findings of the research are presented using descriptive approach with texts and pictures in accordance with qualitative research methodology of this nature. The primary field data collected from the two buildings were gathered between December 2019 and February 2020 as earlier mentioned.

\section{Result, Analysis and Discussion}




\subsection{Senate Building}

The Senate Building in Covenant University serves as the main administrative building for the university. It was commissioned on March 17, 2013 by the Chancellor, Bishop (Dr.) David Oyedepo. The building houses the Senate Chamber of the university as well as offices for the Chancellor, Vice Chancellor, Registrar, Consultancy and Financial Services. The building is made up of eight floors, making it the tallest building in the university campus. The vertical accessibility components found in the building are ramps, steps/staircases and lifts. These features are examined in the following sections.

\subsubsection{Main Entrance Stairs and Ramps}

At the main entrance of the Senate building, both ramps and steps are provided as vertical movement components for users to access the building at the main entrance of the building in conformity with UD requirement, as shown in Plates $1 \mathrm{~A}$ and $1 \mathrm{~B}$.

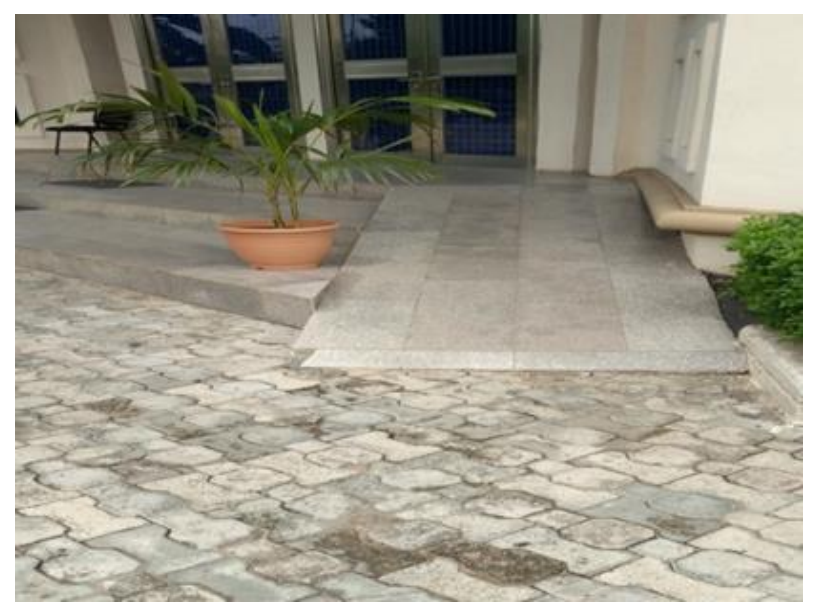

(A)

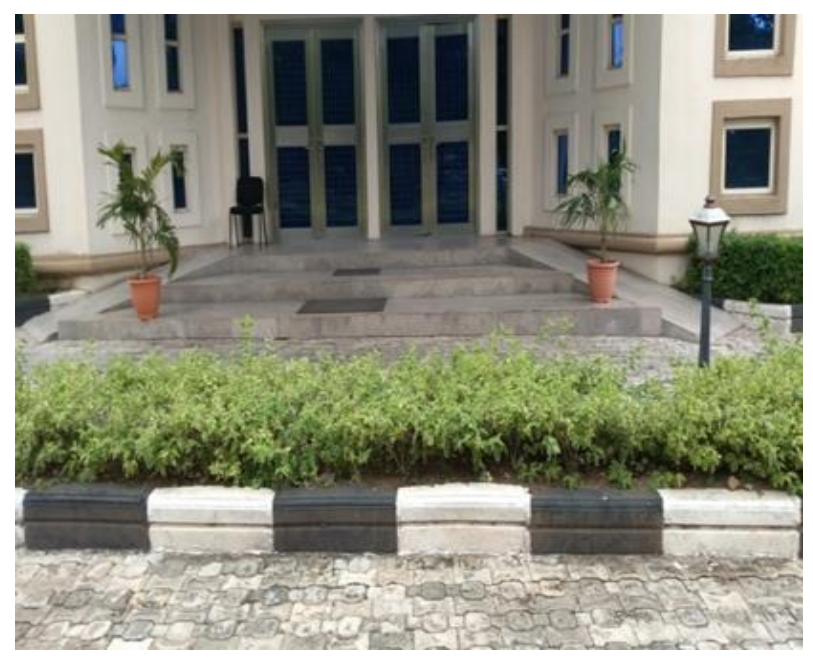

(B)

Plates 1A and 1B. Senate Building Main Entrance Ramps and Steps
Each of the ramps at the main entrance of the Senate building are positioned on either side of the steps at the main entrance, as shown in Plates 1A and 1B. The surfaces of the ramps and step treads are finished with polished granite which are firm, hard and ordinarily non-slippery. However, polished granite is not suitable for outdoor floor spaces due to their slippery nature when they get wet. The steps and ramps surfaces can become slippery and unsafe to use when wet during raining season. This contravenes the safety standard of the UD principles which requires features to be safe to use for users at all times. The height of the ramps is $540 \mathrm{~mm}$, but the ramp to the right-side of the step is $3130 \mathrm{~mm}$ long, while the one on the left-side is 2800 $\mathrm{mm}$ in length. This shows inconsistency in the gradient of the ramp, contrary to UD requirement. Also, the slopes of both ramps are too steep. Their gradients are far higher than the 1 to 20 minimum standard specified for accessible ramps. This makes the ramps uncomfortable and unsafe to use. The effective widths of the ramps which are, $1050 \mathrm{~mm}$ and $1100 \mathrm{~mm}$ also fall short of the minimum acceptable of $1200 \mathrm{~mm}$ for a one-way accessible ramp. The widths are narrow and not suitable for a wheelchair user to conveniently navigate through. In addition, the ramps are not provided with a handrail on either side for the use of those who might need to support themselves while using the ramps in line with UD requirements. Generally, the specifications of both ramps at the entrance of the Senate building fall short of the requirements for an accessible ramp. Their compliance level with UD strategies is low. Likewise, the UD compliance level of the steps at the main entrance of the building is also low. This is because the dimensions of both the step risers $(190 \mathrm{~mm})$ and tread $(900$ $\mathrm{mm})$ are outside the acceptable limit of $180 \mathrm{~mm}$ and 450 $\mathrm{mm}$ respectively. The minimum effective width of the steps is $4600 \mathrm{~mm}$. Due to the large span, this requires that at least one handrail be provided for those who have mobility difficulty to support themselves when climbing or descending the steps. However, no handrail was provided. Also, the treads surfaces may become unsafe when wet as earlier mentioned. Nevertheless, the steps have closed risers which makes them safe to use, especially when dry, as a foot cannot slip through them.

\subsubsection{General Access Staircase}

The Senate building is provided with two internal access staircases. The first one is a general access staircase located at the far left of the main entrance hall and the second is a service and emergency exit staircase situated at the rear end of the building. The two staircases are dog-leg stairs. As the focus of the study is on the main staircase used in high-rise buildings, only the general access stairs were examined. Plates $2 \mathrm{~A}$ and $2 \mathrm{~B}$ are pictorial images of the general access staircase showing the various components of the stairs. 


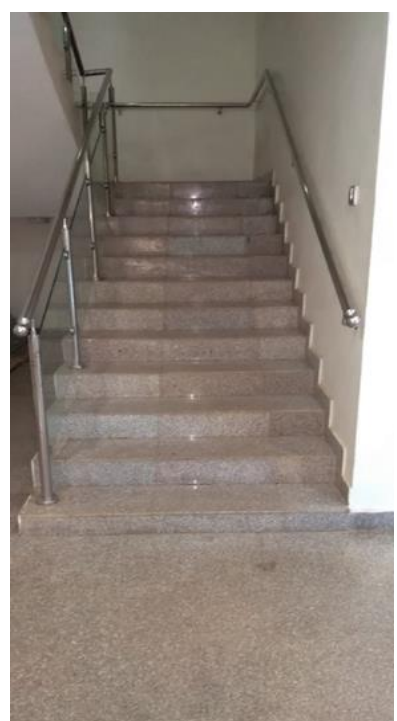

(A)

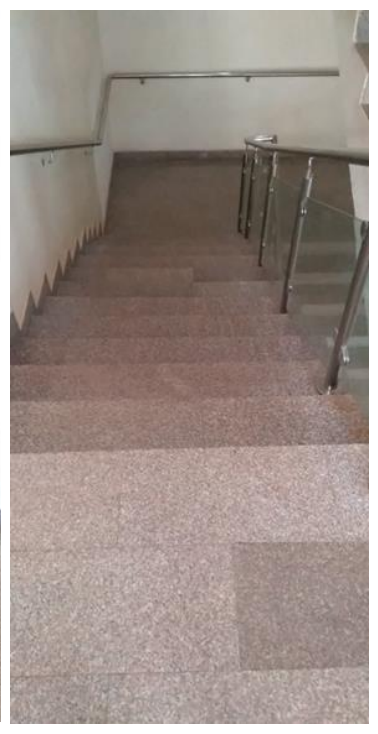

(B)
Plates 2A and 2B. Senate Building General Access Staircase

The general access staircase is a concrete stair finished with polished granite as shown in Plates $2 \mathrm{~A}$ and $2 \mathrm{~B}$. The risers of the stairs are $160 \mathrm{~mm}$ high and generally consistent across the floors in line with UD requirement. Usually stairs risers are expected to be consistent and have heights between $150 \mathrm{~mm}$ and $180 \mathrm{~mm}$. The risers are closed risers which are safe for users as a foot cannot mistakenly slip through them. The treads of the stairs are $290 \mathrm{~mm}$ wide and consistent. Though this dimension is slightly short of the $300 \mathrm{~mm}$ minimum standard requirement for a step, the difference of $100 \mathrm{~mm}$ is considered insignificant to impact negatively on users' convenience. Moreover, the treads are generally consistent in size. The surfaces of the treads and landings of the staircase are also firm, hard and non-slippery in line with UD requirements. The effective width of the stairs and landings is $1400 \mathrm{~mm}$ which is wider than the minimum requirement of $1200 \mathrm{~mm}$ for passage ways. The widths are large enough to allow two or more people to pass side by side. The height of floors to landings is approximately 1800 $\mathrm{mm}$, which is the minimum acceptable requirement in this regard, hence adequate. Each flight of the stairs is made up of an average of 12 risers. This falls within the maximum acceptable limit of 15 steps per flight. The staircases are provided with round stainless-steel handrails on both sides. The handrails height is approximately $950 \mathrm{~mm}$ from the surface of the treads. This dimension conforms with the acceptable height range specified for accessible handrails which is between $900 \mathrm{~mm}$ and $1000 \mathrm{~mm}$. The diameter of the handrails is $50 \mathrm{~mm}$ and conforms with the minimum acceptable diameter of $60 \mathrm{~mm}$ specified for accessible designs. However, a lower handrail was not provided for people of short status and children, in line with UD requirements. Nevertheless, based on the overall findings on the general access staircase in the building, its compliance level with UD parameters is high.

\subsubsection{General Passenger Lift}

Whereas the general access staircase of the Senate building is located to the far left within the main entrance hall, the only general passenger lift in the building is positioned to the opposite far right of the main entrance hall as shown in Figures $3 \mathrm{~A}$ and $3 \mathrm{~B}$.

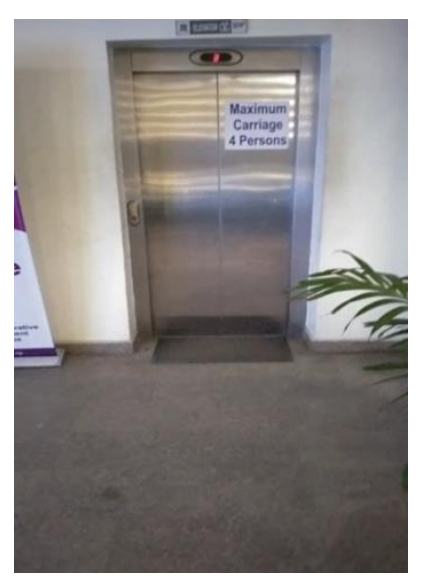

(A)

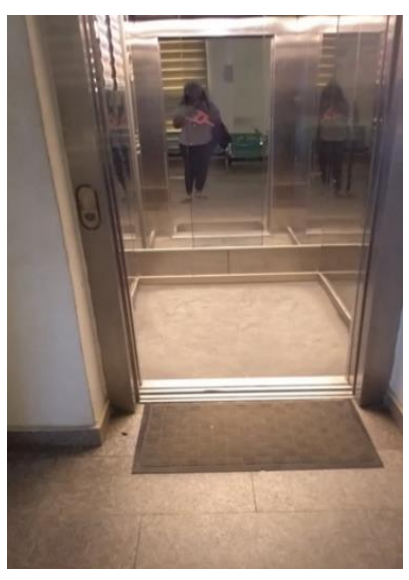

(B)
Plates 3A and 3B. Senate Building General Passenger Lift

The lift shown in Plates $3 \mathrm{~A}$ and $3 \mathrm{~B}$ is a four persons $(630 \mathrm{~kg})$ passenger lift. The lift is provided with an elevator signage at the top of the door for easy identification of the lift by users of the building. The sizes and spaces provided to approach and use the lift on each floor are over $1800 \mathrm{~mm}$ by $1800 \mathrm{~mm}$ which is the minimum requirement in such instance. The lift approach sizes and spaces on each floor of the building are large enough to accommodate several people at a time in conformity with the seventh principle of UD. Though the height of the lift door is $2000 \mathrm{~mm}$ and adequate, the effective width of the door of $800 \mathrm{~mm}$, falls short of the minimum acceptable standard of $950 \mathrm{~mm}$. The internal dimensions of the lift car are $990 \mathrm{~mm}$ by $1380 \mathrm{~mm}$, which also fall short of the minimum standard of $1800 \mathrm{~mm}$ by $1800 \mathrm{~mm}$ for an accessible lift. This implies that a wheelchair user will find it difficult to enter and maneuver within the lift car, contrary to UD requirement. The lift is also not provided with a handrail within the lift car in line with UD safety standard. The handrail is usually needed for users to support themselves when the lift is in motion to avoid falling. The lift control buttons are positioned at accessible heights of between $1030 \mathrm{~mm}$ and $1200 \mathrm{~mm}$. These heights are reachable for most people, including wheelchair users. The lift car is provided with a full-length mirror at the opposite side of the door. Signage that indicates when the lift car gets to a particular floor is provided both inside and outside the lift car. However, it was observed that there is no audible voice prompt to complement the signs for the benefit of those with visual impairment. Nevertheless, the lift is provided with a speaker for communication in case of emergency. The lift floor is firm, hard and non-slippery in conformity with 
UD requirements. The lift door stays open for approximately five seconds before closing when called to action. Its opening and closing speed are steady and reasonable. The speed of the lift car is also steady and reasonable. Based on the overall findings on the lift, the lift is averagely compliant with UD strategies.

Generally, the result on the compliance level of the vertical movement components of the Senate building with UD strategies shows that only the main access staircase within the building complied reasonably with UD strategies, as most of its specifications conform with UD standard requirements. But that of the passenger lift inside the building is considered moderate, as its provision complied averagely with UD strategies. On the other hand, the main entrance steps and ramps all recorded a low UD compliance level to indicate that they are inadequately provided.

\subsection{Centre for Research, Innovation and Discovery (CUCRID) Building}

The CUCRID building comprises of seven floors, making it the second tallest building on the campus of the university. The building serves as the centre for all research, innovation and discovery projects in the institution. The building was also commissioned by the Chancellor, Bishop (Dr.) David Oyedepo in June, 2016, during the convocation week. The building houses start-up laboratories, research and technology laboratories, the school of postgraduate studies and several other facilities meant for promoting research, innovation and discovery in the university. Just like the Senate building, the vertical movement components provided for the building are ramps, steps/staircases and lifts. These components are examined as follows:

\subsubsection{Main Entrance Ramp and Steps}

At the main entrance of the CUCRID building, a ramp and steps are the two vertical movement components provided for users to access the building from the approach in line with UD requirement, as shown in Plate 4A and 4B.

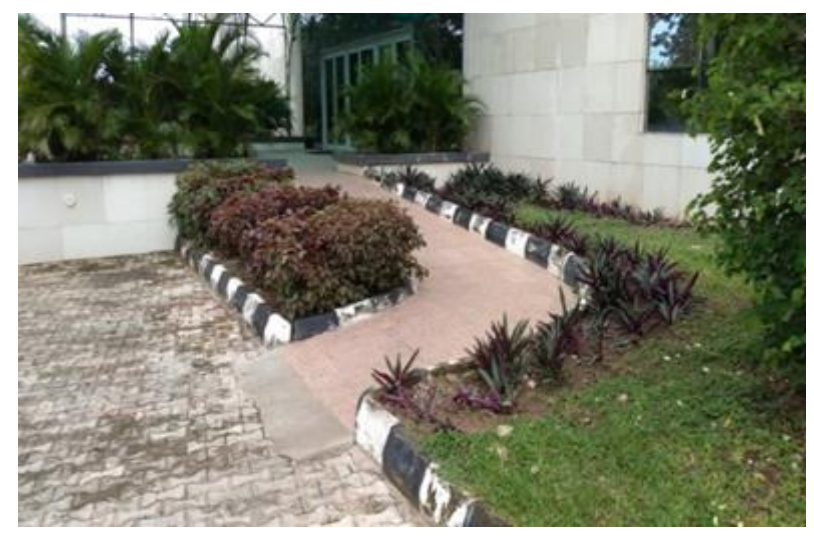

(A)

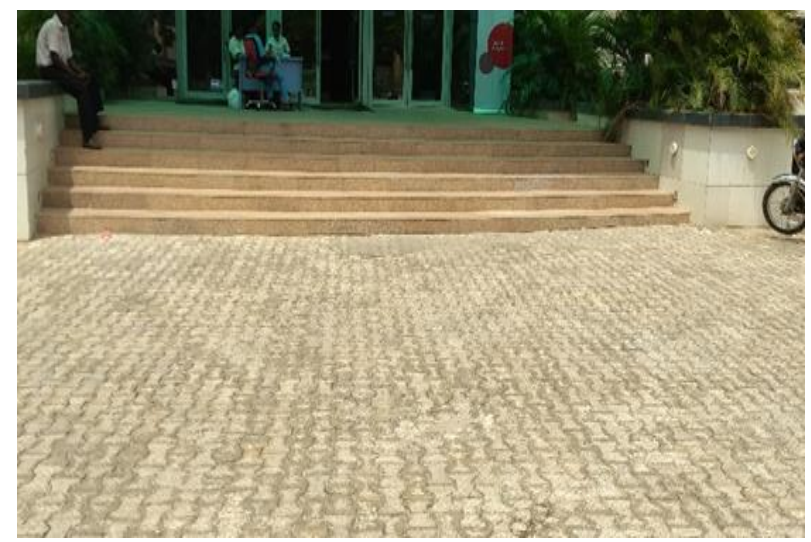

(B)

Plates 4A and 4B. Main Entrance Ramps and stairs

The ramp at the main entrance of the CUCRID building is located to the right-side of the main entrance steps. Both the ramp and the steps open into a covered entrance foyer. The surfaces of the ramp and step treads are finished with hard and firm granite tiles that are non-slippery, as shown in Plates $4 \mathrm{~A}$ and $4 \mathrm{~B}$. The height of the ramp is $900 \mathrm{~mm}$ with a length of $9000 \mathrm{~mm}$. The slope of the ramp is steep. Its gradient is steeper than the 1 to 20 minimum standard specified for an accessible ramp. The ramp is also not provided with handrails on both sides in conformity with standard ramp requirement. This makes the ramp uncomfortable to climb or descend from. However, the ramp's effective width of $1600 \mathrm{~mm}$ is more than the minimum standard of $1200 \mathrm{~mm}$ for a one-way accessible ramp. To a large extent, the specifications of the ramp at the entrance of the CUCRID building fall short of the requirements for an accessible ramp. This implies that its compliance level with UD strategies is low.

However, the UD compliance level of the main entrance steps is high. This is because, both the risers and treads of $150 \mathrm{~mm}$ high and $450 \mathrm{~mm}$ deep respectively, are within the acceptable dimensions of standard step requirements stated earlier. The risers are also closed risers in line with UD requirement. However, the steps have an effective width of $8450 \mathrm{~mm}$. This necessitates the provision of at least a handrail due to the large span, as explained earlier. However, no handrail was provided. The purpose of the handrail is to enable persons with mobility difficulty to be able to support themselves when climbing or descending the steps. Nevertheless, the steps specifications are to a large extent compliant with UD strategies, hence adjudged reasonable.

\subsubsection{General Access Staircases}

The CUCRID building is provided with a total of four staircases out of which two are located in the main entrance hall behind the reception desk, serve as the general access staircases. The other two are situated at the far right and far left inside the building and serve as fire escapes and service 
staircases, as well as compliment the two general access staircases. Based on the scope of the study, only the general access staircases were examined. The two staircases are identical. They are winding in nature, as shown in Plates $5 \mathrm{~A}$ and $5 \mathrm{~B}$.

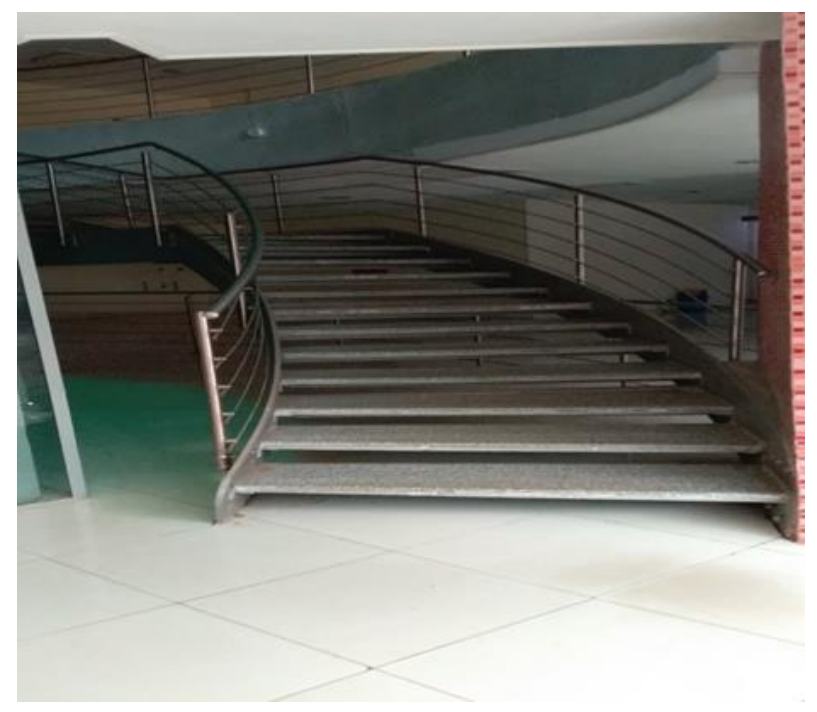

(A)

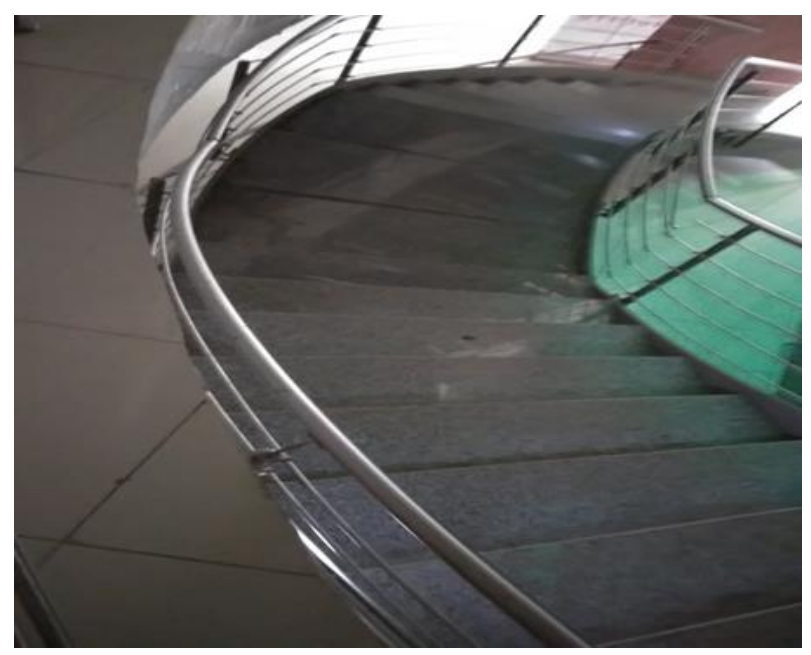

(B)

Plates 5A and 5B. CUCRID General Access Staircases

The general access staircases in the CUCRID building are steel framed structures with their treads and intermediate landing platforms anchored to the steel frames, as shown in Plates 5A and 5B. The dimensions of the treads are $400 \mathrm{~mm}$ and consistent in conformity with UD requirements. The size of the treads also falls within the acceptable range of between $300 \mathrm{~mm}$ and $450 \mathrm{~mm}$ for accessible designs. The surface of the treads was finished with polished granite that is hard, firm and non-slippery in line with UD requirement. However, the risers are not consistent contrary to UD requirement. They are largely between $150 \mathrm{~mm}$ and $170 \mathrm{~mm}$ in height. In some cases, they are as low as $70 \mathrm{~mm}$ and as high as $190 \mathrm{~mm}$, which are outside the acceptable height range of between $150 \mathrm{~mm}$ and $180 \mathrm{~mm}$ for steps. The risers are also open risers which are considered not safe as a user's foot may mistakenly slip through them. This makes the stairs not completely safe to climb or descend from as anyone may miss a step and fall on them. The effective width of the stairs is $1470 \mathrm{~mm}$, while that of the landings is $2000 \mathrm{~mm}$. These dimensions are adequate as they are more than the acceptable minimum limit of $1200 \mathrm{~mm}$ recommended for passage ways. The staircases flights are made up of an average of 12 risers. This falls within the maximum allowable limit of 15 steps per flight. The staircases are also provided with round stainless-steel handrails of $50 \mathrm{~mm}$ diameter on either side of the stairs. The handrails height range are largely between $1000 \mathrm{~mm}$ and $1100 \mathrm{~mm}$. These specifications of the handrails are fairly consistent with standard handrail requirements. However, few areas of the handrails have heights lower than the acceptable limit of $900 \mathrm{~mm}$. In a case, it is as low as $700 \mathrm{~mm}$ which is not safe. Also, a lower handrail was not provided for in line with UD requirement. Nevertheless, based on the findings on the two general access staircases in the CUCRID building, their overall compliance level with UD strategies is average.

\subsubsection{Lifts}

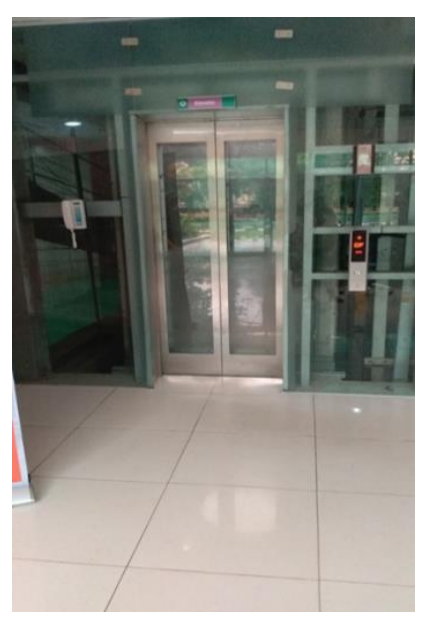

(A)

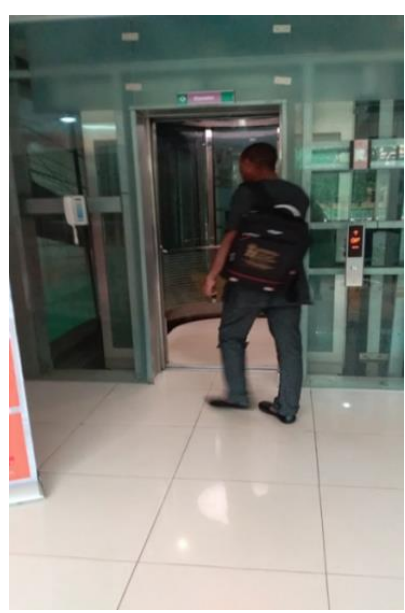

(B)
Plates 6A and 6B. CUCRID Building General Passenger Lifts

The general access lifts in the CUCRID building are situated between the general access staircases within the main entrance hall. Though four lift shafts are provided, only two of them are equipped with lift cars used for vertical movement of users within the building, as shown in Plates 6A and 6B.

Each of the two passenger lifts shown in Plates 6A and $6 \mathrm{~B}$ is a fifteen persons $(1000 \mathrm{~kg})$ passenger lift. An elevator signage was provided at the top of the lift doors for users to be able to easily identify the lift. The sizes and spaces for approach and use of the lift provided on each floor is adequate, as their dimensions are over the $1800 \mathrm{~mm}$ by $1800 \mathrm{~mm}$ minimum requirement specified for accessible 
lifts. The sizes of the spaces are wide enough to accommodate several persons at a time in line with the seventh principle of UD. The height of the lift door is 2100 $\mathrm{mm}$ and within the acceptable limit of $2000 \mathrm{~mm}$. However, the effective width of the lifts doors is $800 \mathrm{~mm}$. This falls short of the acceptable limit of $950 \mathrm{~mm}$. The effective lengths and widths of the lift cars is $1700 \mathrm{~mm}$ and $1200 \mathrm{~mm}$ respectively. These dimensions also fall short of the minimum size of $1800 \mathrm{~mm}$ by $1800 \mathrm{~mm}$ specified for accessible lifts. Wheelchair users will also most likely find it challenging when entering, as well as maneuvering within the lift cars. In addition, the lift cars are built with transparent glass panels which might not be suitable for people who are scared of heights. But standard handrails of $950 \mathrm{~mm}$ are provided within the lift cars in conformity with UD safety standard. The handrails are used by users to support themselves when the lift is in motion. Most of the control buttons of the lift are positioned at accessible heights of between $950 \mathrm{~mm}$ and $1200 \mathrm{~mm}$. Just two of the buttons whose height are $1300 \mathrm{~mm}$ and $1600 \mathrm{~mm}$ are positioned outside the accessible height range. Signage that indicates when the lift car gets to a particular floor was provided inside, as well as outside the lift car. Nonetheless, it was also observed that no audible voice prompt was made available to complement the signs for the benefit of people with visual impairment. But the lift has a speaker in it for communication in case of emergency. The floors of the lift cars are firm, hard and non-slippery in line with UD requirements. The lift doors stay open for approximately five seconds before being closed. The doors opening and closing speed, as well as the speed of the lift cars, are steady and reasonable. In view of the general findings on the lifts, their compliance level with UD strategies is average.

In general, the findings on the compliance level of the vertical movement components of the CUCRID building with UD strategies indicates that only the main entrance steps complied reasonably with UD strategies, as majority of its provisions are in line with UD requirements. The main entrance ramps recorded a low UD compliance level as most of its provisions do not conform with UD requirements. But, the compliance level of the two passenger lifts and the two general access staircases within the building with UD strategies, is moderate. This is because their provisions are averagely compliant with their respective UD strategies.

\subsection{Discussion of Findings}

The findings from the analysis of the field data gathered on the vertical movement components of the Senate and CUCRID buildings in Covenant University presented in Sections 4.1 and 4.2, show that both high-rise buildings are provided with at least a ramp and steps at their main entrances to enable users gain access into the buildings. Similarly, each of the building is provided with at least a general access staircase and a lift within the building to enable users transport themselves from one floor to the other. This indicates that conscious attempts were made at the main entrances and within both buildings to provide for the vertical accessibility needs of all potential users, including the physically challenged, in conformity with UD requirements.

However, a detailed examination and analysis of the vertical movement components show that majority of their provisions do not conform with UD strategies. Only the steps at the main entrance of the CUCRID building and the general access staircase inside the Senate building, recorded high UD compliance levels, as most of their provisions conformed with UD requirements. Hence, only these two vertical movement features of the high-rise buildings are adjudged to be reasonably compliant with UD requirements. The provisions of the lifts in both buildings and that of the general access staircases within the CUCRID buildings are adjudged moderately compliant with UD requirements. This is because their provisions were found to averagely comply with UD strategies. However, the ramps at the main entrances of both buildings, as well as the steps at the approach of the Senate building, all recorded a low UD compliant level, as most of their provisions were found not to comply with UD strategies.

It is apparent from the result that the provisions of the vertical accessibility components in the high-rise buildings are inadequate. The most affected are features commonly useful for the physically challenged. For instance, all the ramps at the main entrances of the buildings recorded low UD compliance levels, while the provisions of the lifts in both buildings are barely averagely compliant with UD requirements. Only one of the main entrance flights of steps and a general access staircase, which are usually accessibility features provided for the benefit of able-bodied persons within one of the buildings, recorded high UD compliant ratings. This goes to show that the physically challenged, particularly those who use mobility aid such as wheelchair users, as well as the aged and workers pulling or pushing trolleys, will most likely find it challenging using the vertical movement features components situated in the high-rise buildings.

Generally, the findings of the study corroborate several other previous studies that found that people living with one form of disability or another are often not adequately provided for in public buildings in terms of their accessibility and usability needs, compared to provisions made for able-bodied persons $[9,29,31,14,15,3,17]$. The result on ramps specifically tallied with the results of Sholanke, Adeboye \& Alagbe; Sholanke, Adeboye, Oluwatayo \& Alagbe; Yusita, Yong \& Thamrin [31,3,17]. The said authors found that ramps provided at the main entrances of public buildings they investigated (academic buildings in universities in Nigeria and shopping malls in Surabaya), are most likely to hinder accessibility for the physically challenged users of the buildings as a result of 
various inadequacies identified that contravene UD requirement. Few of such inadequacies are lack of handrails attached to the ramps and steeped ramp gradients. The result also conformed with the findings of Sholanke [30] that discovered that academic buildings in selected universities in Nigeria are largely inadequately equipped with vertical movement features suitable for the use of the physically challenged, despite most of the buildings being storey buildings comprising more than two floors.

In general, the vertical accessibility components of high-rise buildings in Covenant University are not satisfactorily compliant with UD strategies. The buildings are not sufficiently equipped with enough vertical movement provisions that can guarantee the promotion of social inclusivity in educational environments in the study area. While able-bodied persons might not find it difficult to independently gain access into the building from their main entrances, as well as travel up and down between floors inside the buildings, the physically challenged, especially mobility aid users, will most likely find it challenging to do same.

\section{Conclusions}

The study was conducted to examine the compliance level of vertical movement components of high-rise buildings with universal design strategies in Covenant University, Ota in Nigeria, in order to identify areas for further improvements, towards contributing to ways of promoting social inclusion in educational environments. The Senate building and the Centre for Research, Innovation and Discovery building are the two buildings that fall under the category of high-rise buildings in the university campus. A summary of areas found not to comply with universal design requirements, hence call for improvements in the buildings include: steep ramp gradients, narrow ramp widths, lack of handrails to ramps, inadequate and inconsistent step risers and treads, inadequate staircases handrails and lifts specifications. Lift provisions that fall short of universal design minimum requirements are their effective door widths, effective car sizes, heights of some lift control button and lack of support handrails within a lift car. In general, the findings show that adequate vertical movement provisions are not made in the high-rise buildings. Accessibility components usually needed by people with mobility impairment are the most affected. The general implication of the results is that the buildings lack enough vertical movement components for promoting social inclusion in the university campus.

The key contribution to knowledge of the study is the provision of empirical data on the compliance level of vertical accessibility components of high-rise buildings with UD strategies in the study area. The study also revealed specific areas of the vertical movement components in the said high-rise buildings that contravened UD requirements and require attention. The paper stands to increase awareness on the importance of conforming with UD strategies in the development of accessible academic environments. It further draws attention to the inadequate and lack of appropriate provisions for the handicapped members of the society in the design and development of public environments. In general, the paper has established a new empirical based study from where further studies can be generated.

Based on the findings of the study, the following recommendations are made: where possible, the buildings should be retrofitted with necessary accessibility provisions where they are lacking or inappropriately provided; measures should be put in place by the university management to ensure that further high-rise buildings in the university are designed and developed to comply with universal design strategies generally, especially with regards to vertical movement provisions; there is also a need to review building development guidelines in the study area to ensure that they are capable of promoting social inclusion in the development of the built-environment; building professionals, especially architects should always take care to make adequate provisions for the accessibility needs of everyone, including people with disabilities, in the development of high-rise buildings. Conscious efforts should be made to ensure easy vertical movement for all potential users in such buildings.

Lastly, the authors recognise that, because the study is a case study limited to Covenant University high-rise buildings, its findings cannot be generalised beyond the university setting. Consequently, similar studies should be conducted in other universities in Nigeria and other countries around the globe to help provide a broader insight into the subject matter. Such studies are necessary as they are likely to provide more insight into possible areas that require improvements in the development of high-rise buildings in academic settings, towards promoting social inclusion in the development of inclusive learning environments. For the same reason, similar studies could be extended outside the university environment to include office buildings, hotels and residential apartment blocks. An objective approach was adopted to conduct this study. Further studies can employ subjective means that rely on users' perception to evaluate the effectiveness of vertical movement components in high-rise in meeting users' needs.

\section{Acknowledgements}

The authors are appreciative of Covenant University management for the support, necessary resources and conducive atmosphere provided to carry out this study. The peer reviewers whose suggestions provided the authors the opportunity to improve the quality of the 
earlier manuscript are acknowledged and appreciated. The authors are also appreciative of all authors whose research materials were consulted in the course of gathering background information for the paper. All of such scholarly materials were duly cited in the work and referenced in the following section.

\section{REFERENCES}

[1] Hadley, B. (2017). Vertical School Design. Journal Series on Vertical School Design.

[2] Salmen, J. P. S. (2011). Universal Design for Academic Facilities. New Directions for Student Services, Volume 2011, Issue 134

[3] Sholanke, A. B., Adeboye, A. B., Oluwatayo, A. A. \& Alagbe, O. A. (2016). Evaluation of Universal Design Compliance at the main entrance of selected Public buildings in Covenant University, Ota, Ogun state, Nigeria. 3rd International Conference on African Development Issues (CU-ICADI 2016).

[4] Times Higher Education (2019). World University Rankings. Retrieved November 12, 2019 from https://www.timeshigh ereducation.com/world-university-rankings.

[5] Covington, G. A. (1996). Access by Design. John Wiley \& Sons Publishers. ISBN 10: 0471287261

[6] The City of Calgary (2010). Universal Design Handbook. Canada. The City of Calgary Printing Press

[7] Gulliksen, J., Yngling, A. A., Persson, H. \& Ahman, H. (2014). Universal Design, Inclusive Design, Accessible Design, Design for All: Different Concepts-One Goal? On the Concept of Accessibility- Historical, Methodological and Philosophical Aspects. Universal Access in the Information Society.

[8] Izzo, M. V. (2012). Universal Design for Learning: Enhancing Achievement of Students with Disabilities. Procedia Computer Science, 14: 343-350

[9] Sholanke, A. B., Adeboye, A. B. \& Alagbe, O. A. (2019a). Adequacy of Ogun State Building Development Regulatory Legislation in Promoting Universal Design Practice in Nigeria. International Journal of Civil Engineering and Technology (IJCIET), Volume 10, Issue 04, pp. 484-510

[10] Steinfield, E. (1994). Center for Inclusive Design and Environmental Access. Sixth Ibero-American Conference on Accessibility, Center for Independent Living, Rio De Janeiro, Brazil.

[11] Sholanke, A., Adeboye, A., Alagbe, O., Fadipe, D. \& Iyoha, J. (2018). Universal Design Framework for the Development of Adaptable Architectural Studios for Learning Environments. INTED2018 Conference, Valencia, Spain.

[12] Copeland, E. (2014). Promoting Universal Design in Public Buildings: An Action Research Study of Community Participation. A thesis submitted to Auckland University of Technology, New Zealand.
[13] Rossetti, R. (2010). Ten Myths About Universal Design. Action Magazine. Texas, USA.

[14] Hibatullah, S. (2018). An Evaluation of the School of Engineering Buildings at the University of Jordan with Regard to Accessibility. A Journal from the Architecture Engineering Department, The University of Jordan, Amman, 11942, Jordan.

[15] Ibem, E. O., Oni, O. O., Umoren, E. \& Ejiga, J. (2017). An Appraisal of Universal Design Compliance of Museum Buildings in Southwest Nigeria. International Journal of Applied Engineering Research Volume 12, Number 23.

[16] Mustaquim, M. M. (2015). A Study of Universal Design in Everyday Life of Elderly Adults. 6th International Conference on software Development and Technologies for Enhancing Accessibility and Fighting Info-exclusion (DSAI 2015).

[17] Yusita, K., Yong, S. \& Thamrin, D. (2012). Entrance and circulation facilities of malls in Surabaya: A universal interior design application. ASIA Pacific International Conference on Environment-Behavior Studies Mercure Le Sphinx Cairo Hotel, Giza, Egypt, 31 October - 2 November, 2012.

[18] Kadir, S. A. \& Jamaludin, M. (2011). Applicability of Malaysian Standards and Universal Design in Public Buildings in Putrajaya. ASEAN Conference on Environment-Behavior Studies, Savoy Homann Bidakara Bandung Hotel, Badung, Indonesia, 15-17 June 2011.

[19] Development Control Regulation (2015). Comprehensive Capacity Building Programme $(C C B P)$. Ministry of Urban Development, Government of India.

[20] Emporis Standards (2020). Data Standards: High-rise Building (ESN 18727). Retrieved March 23, 2020, from https://www.emporis.com/building/standard/search/high-ris e

[21] National Fire Protection Association (NFPA) (2018). National Fire Protection Association 5000, Building Construction and Safety Code.

[22] National Building Code (2006). The Federal Republic of Nigeria National Building Code, (1st Edition). LexisNexis Butterworths

[23] The Building Regulations (2015). Access to and Use of Buildings Other than Dwellings: Approved Document M Volume 2. Retrieved June 27, 2016, from Planning Portal: https://www.planningportal.co.uk/info/200135/approve_doc uments/80/part_m_-_access_to_and_use_of_building/2

[24] Inclusive Mobility (2012). A Guide to Best Practices on Access to Pedestrian and Transport Infrastructure. Retrieved March 10, 2016, from assets.publishing.service.g ov.uk:

[25] Department of Justice (2010). 2010 ADA Standards for Accessible Design. Retrieved March 27, 2016, from www.ADA.gov:

https://www.ada.gov/2010ADAstandards_index.htm

[26] Building for Everyone (2010). Building for Everyone: A Universal Design Approach. Retrieved November 26, 2018, from URL http://www.universaldesign.ie

[27] Yin, R. K. (2014). Case Study Research: Design Methods 
(5th edition). Thousand Oaks, CA, USA.

[28] Noor, K. B. M. (2008). Case Study: A Strategic Research Methodology. American Journal of Applied Sciences, Volume 5, Issue 11.

[29] Sholanke, A. B., Adeboye, A. B. \& Alagbe, O. A. (2019b). Design Solutions Creating Barriers to Achieving Universal Design Compliance of Academic Buildings in Universities in Nigeria. International Journal of Civil Engineering and Technology (IJCIET), 10 (1): 671-690.
[30] Sholanke, A. B. (2019). Compliance of Academic Buildings with Universal Design Parameters in Selected Universities in Ogun State, Nigeria. PhD Thesis, Department of Architecture, Covenant University, Ota, Ogun State, Nigeria.

[31] Sholanke, A. B., Adeboye, A. B. \& Alagbe, O. A. (2019c). Design Solutions Creating Barriers to Achieving Universal Design Compliance of Academic Buildings in Universities in Nigeria. International Journal of Civil Engineering and Technology (IJCIET), 10 (1): 671-690. 